PROC. OF JSCE

No. 337, September 1983

[Technical Note]

\title{
INFLUENCE OF ROOT IRREGULARITY ON FATIGUE STRENGTH OF PARTIALLY-PENETRATED LONGITUDINAL WELDS
}

\author{
By Chitoshi MIKI*, Fumio NISHINO**, Toshimi SASAKI*** \\ and Takeshi MORI****
}

\section{INTRODUCTION}

Partially-penetrated longitudinal weldings are often used for assembling box-section members. In the previous studies ${ }^{1) \sim 3}$, it was shown that weld defects such as blowholes existed at the root of this joint and these defects decreased fatigue strength of the joint. In the case that root gap of this joint becomes wide, some melted weld metal spills down into the root gap of the joint. After the welding is completed, the weld metal stays in the root gap as if it is hanging-down from the root. In the pilot members for Ohnaruto Bridge, hanging-downs remained when root gap was wider than $0.6 \mathrm{~mm}^{4}$ ) (Fig. 1). This root irregularity causes stress concentration and may

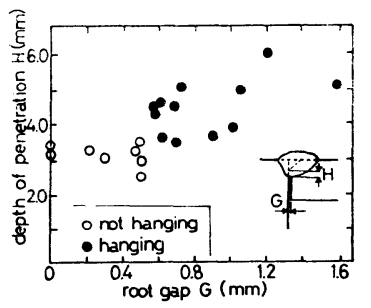

Fig. 1 Depth of weld penetration for various root gaps). reduce the fatigue strength.

The main objective of this study is to examine the influence of this root-irregularity on the fatigue strength of this joint and to clarify the properties of initiation and propagation of fatigue crack experimentally. Fracture mechanics analysis of fatigue crack propagation is also carried out to predict the fatigue life of this joint.

\section{SPECIMEN AND TESTING METHOD}

The material used is $600 \mathrm{MPa}$ class quenched and tempered steel. Mechanical properties and chemical compositions of the steel are shown in Table 1. Plates of $620 \mathrm{~mm}$ in length, $120 \mathrm{~mm}$ in width and $17 \mathrm{~mm}$ in thickness were welded longitudinally with the root gaps of $0,0.5,1.0$ and $2.0 \mathrm{~mm}$. Prior to regular welds, the welds for sealing the root had been done by $\mathrm{CO}_{2}$ arc welding process. The longitudinal welds were placed by automatic submerged arc welding process. Then specimens were cut out from these welded plates. Fig. 2 shows the configuration and dimensions of specimens. Specimen made as 0 , $0.5,1.0$ and $2.0 \mathrm{~mm}$ of root gaps are called as G0, G0.5, G1 and G2 specimen, respectively. Due to the weld shrinkage, actual root gaps of G0, G0.5, G1 and G2 specimens become 0, 0 $0.1,0.6$ and $1.4 \sim 1.5 \mathrm{~mm}$ after weldings. In G0

Table 1 Mechanical properties and chemical compositions.

\begin{tabular}{c|c|c|c|c|c|c|c}
\hline \multicolumn{2}{c|}{ Mechanical Properties } & \multicolumn{3}{c}{ Chemical Compositions } \\
\hline $\begin{array}{c}\text { yield point } \\
(\mathrm{MPa})\end{array}$ & $\begin{array}{c}\text { tensile strength } \\
(\mathrm{MPa})\end{array}$ & $\begin{array}{c}\text { elongation } \\
(\%)\end{array}$ & $\begin{array}{c}\mathrm{C} \\
\times 100\end{array}$ & $\begin{array}{c}\mathrm{Si} \\
\times 100\end{array}$ & $\begin{array}{c}\mathrm{Mn} \\
\times 100\end{array}$ & $\begin{array}{c}\mathrm{P} \\
\times 1000\end{array}$ & $\begin{array}{c}\mathrm{Cu} \\
\times 1000\end{array}$ \\
\hline 560 & 650 & 36 & 15 & 24 & 133 & 21 & $\begin{array}{c}C_{e q} \\
\times 100\end{array}$ \\
\hline
\end{tabular}

* Member of JSCE, Dr. of Eng., Associate Professor, Dept. of Civil Engineering, Tokyo Institute of Technology

** Member of JSCE, Ph. D., Dr. of Eng., Professor, Dept. of Civil Engineering, University of Tokyo
*** Member of JSCE, Reseach Associate, Dept. of Civil Engineering, University of Tokyo

**** Member of JSCE, M. Eng., Reseach Associate, Dept. of Civil Engineering, Tokyo Institute of Technology 


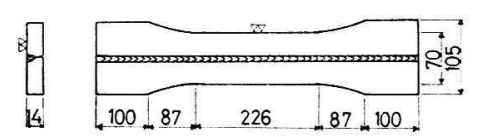

Fig. 2 Configuration and dimensions of specimen.

and G1 specimens, no hanging-downs of weld metal are observed. Hanging-downs of weld metal are observed in G1 and G2 specimens. G2 specimens contain remarkable hanging-downs of weld metal.

The measured value of welding residual stress was about $180 \mathrm{MPa}$ in tension at the center of specimen.

Fatigue tests were performed by using Amslertype and servo-type testing machines of 500 $\mathrm{kN}$ in dynamic capacities. Fatigue loadings were repeated-tension of $20 \sim 30 \mathrm{MPa}$ in minimum stress. Load waveform was sinusoidal and its frequency was $2 \sim 10 \mathrm{~Hz}$.

\section{TEST RESULTS}

\section{(1) Fatigue strength}

Fig. 3 shows the relation between stress range $S_{r}$ and fatigue life to failure $N_{f}$. Fatigue strengths of G0 and G0.5 specimens are almost equal and they are significantly higher than these of G1 and G2 specimens. Fatigue strength of G1 specimen is slightly higher than that of G2 specimen. The Honshu-Shinkoku Bridge Authority recently adopted the design allowable stress range for the corner weld ${ }^{5)}$ as shown in Fig. 3. All present test results are above this line. $S_{r}-N_{f}$ relations for welded joints with large blowholes and without blowholes obtained in previous study ${ }^{2}$ are also shown in Fig. 3. The dimensions of specimens are equal to those in this study and the steel used is the same grade. The average of large blowhole is $3.0 \mathrm{~mm}$ wide and $4.4 \mathrm{~mm}$ long. Fatigue test results of $\mathrm{G} 2$ specimens are plotted

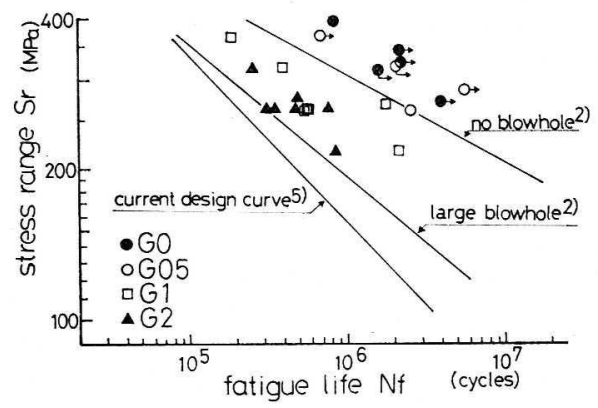

Fig. 3 Results of fatigue tests. above the $S_{r}-N_{\digamma}$ line for large-blowhole specimens and test results of $\mathrm{G} 0$ and $\mathrm{G} 0.5$ specimens are located above the $S_{r}-N_{f}$ line for no-blowhole specimens. Therefore, the influence of hangingdowns of weld metal on faitgue strength is about the same degree as that of large blowholes in previous study.

\section{(2) Initiation of Fatigue Crack}

After fatigue tests, several specimens were opened along the weld line to observe the degree of irregularity at the weld root and fatigue cracking. Photo 1 shows the these exposed surfaces.

In G0 and G0.5 specimens, no weld metal hang down into the root gap of the joint, and no fatigue crack is observed. In G1 and G2 specimens, many inherent partially propagating fatigue cracks are observed. These cracks initiate and propagate from the concave portions of hanging-downs at which stress concentration is high.

The degree of stress concentration at the concave portion is depends on the depth of hanging-down and the radius of concave point. In all observed concave points, the shape is very sharp and its radius is nearly equal to zero. The depth of the hanging-down of weld metal was measured and the results are shown as histograms in Fig. 4. Hatched portion and dotted portion in Fig. 4 indicate that partially propagating cracks were found at the both side and one side of the hanging-down, respectively. Hollow portion shows the hanging-downs with no cracks. In

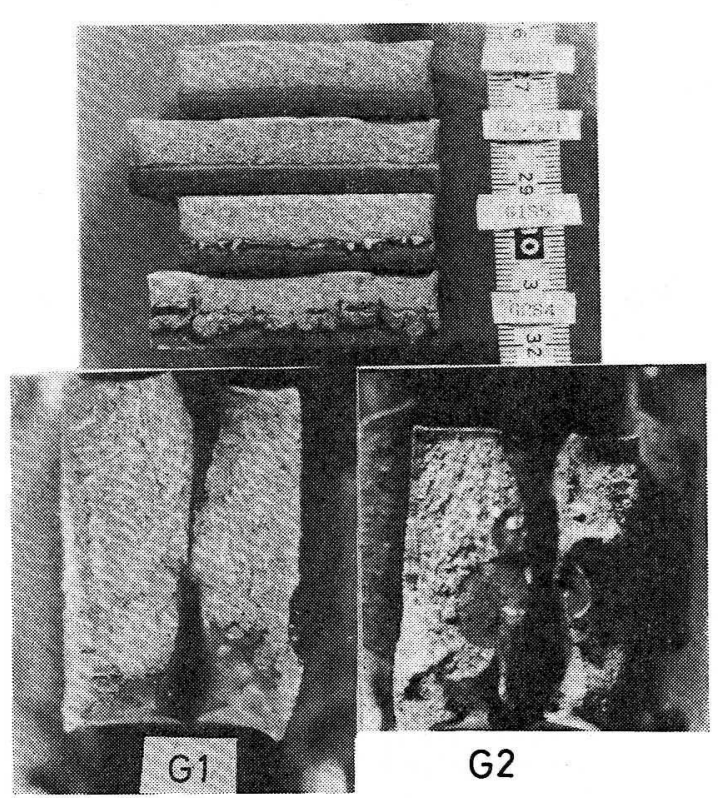

Photo 1 Condition of root face and partially propagating crack. 


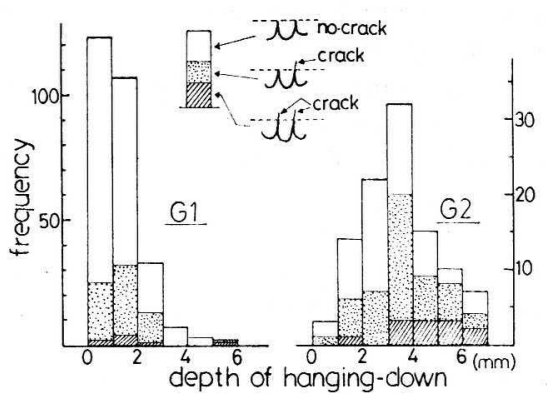

Fig. 4 Histogram for the depth of hangingdown.

G2 specimens, as the hanging-down of weld metal becomes deep, the probability of fatigue crack occurrence increases. However, such trend are not applicable to $\mathrm{G} 1$ specimens.

\section{(3) Propagation of Fatigue Crack}

In order to observe fatigue crack initiation and propagation behavior, beach mark test was carried out. The load history is shown in Fig. 5 along with the fracture surface. This fatigue crack initiates at the corner of root gap in the concave portion of hanging-downs, and propagates rapidly along the surface of weld metal at
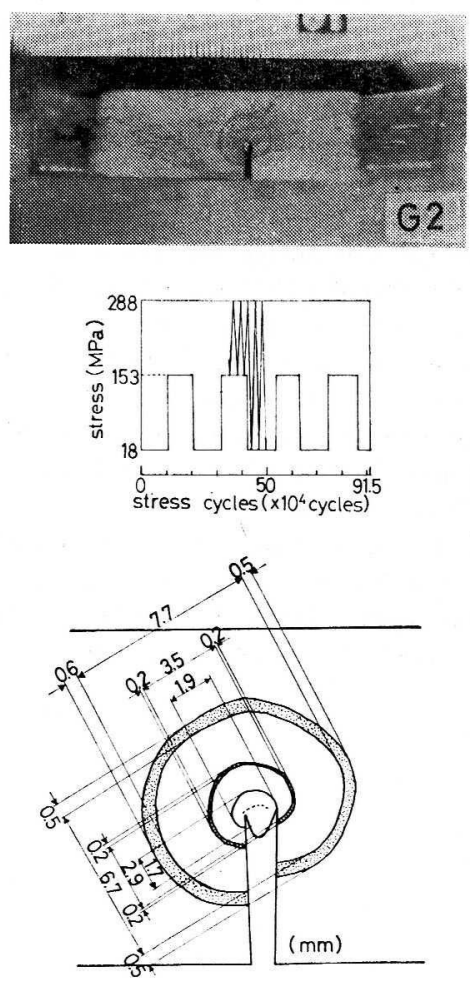

Fig. 5 Result of beach mark test.

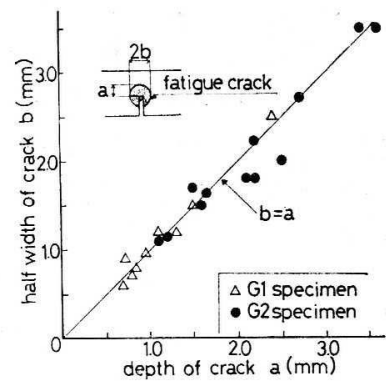

Fig. 6 Shape of fatigue crack.

the root. Then, this crack grows to become circular shape. The stress range was reduced to one half four times during the test and four beach marks appeared on the fracture surface. It means that the first beach mark is formed by the first stress range reduction. Therefore, this fatigue crack has already initiated before $10^{5}$ stress repetitions.

The surfaces of partially propagating fatigue cracks were exposed by rupturing perpendicular to the welds, and the shapes of these cracks were measured. These crack surfaces are shown in Photo 1. Fig. 6 indicates the depth of partially propagating crack from fusion line $a$ and the half width of this crack $b$. The minimum value of $b$ observed in G1 and G2 specimen is 0.6 and 1.1 $\mathrm{mm}$. The shapes of all measured cracks are almost circular. The root gaps of $\mathrm{G} 1$ and $\mathrm{G} 2$ specimens are 0.6 and $1.4 \mathrm{~mm}$. Therefore, after the width of fatigue crack becomes about two times as wide as the width of root gap, the shape of fatigue rack is circular.

\section{PREDICTION OF FATIGUE LIFE}

Since most of the fatigue life of welded joint with root irregularity is spent in the propagation of fatigue crack, fatigue life of this joint can be evaluated by using the fracture mechanics concepts. Fatigue crack propagation life is predicted on the basis of following assumptions.

(1) Fatigue crack originates from the defect at the middle of plate-thickness. Initial defect is regarded as a circular crack (a penny-shaped crack) and its diameter is equal to the width of root gap.

(2) Fatigue crack propagates in circular. Therefore, stress intensity factor $K$ is given by following equation.

$$
K=S \sqrt{\pi a} \cdot \frac{2}{\pi} \sqrt{\sec (\pi a / t)}
$$

$\{S\}$ : nominal stress, $a$ : radius of crack,

$t$ : thickness of specimen 


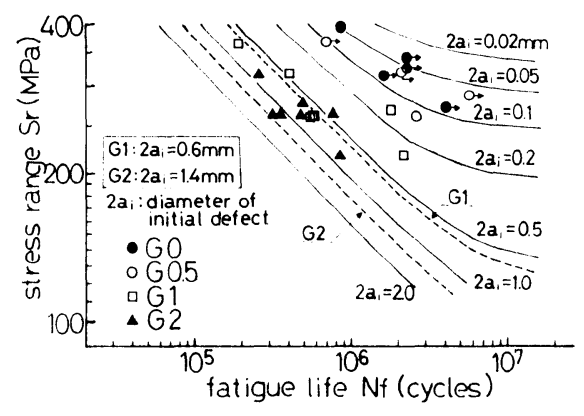

Fig. 7 Predicted $S_{r}-N_{f}$ relations and test results.

(3) The diameter of final crack is equal to $90 \%$ of specimen-thickness.

(4) For the relation between the rate of fatigue crack propagation $d a / d N$ and stress intensity factor range $\Delta K$, equation (2) is employed $^{6}$.

$$
\begin{aligned}
& d a / d N=5.47 \times 10^{-12}\left(\Delta K^{3.0}-2.5^{3.0}\right) \cdots \cdots \cdots(2) \\
& d a / d N: \mathrm{m} / \mathrm{cycle}, \quad \Delta K: \operatorname{MPa} \sqrt{m}
\end{aligned}
$$

Predicted life for various sizes of initial defects $\left(a_{i}\right)$ and test results are compared in Fig. 7. In this figure, broken lines indicate predicted $S_{r}-$ $N_{f}$ relations for G1 and G2 specimens. These predicted lines are close to the experimental results. Therefore, it is valid that initial defect is assumed to be penny-shaped crack having a diameter equal to the width of root gap.

\section{CONCLUSIONS}

The results obtained in this study are as follows.

(1) Fatigue strengths of joints with no root irregularities are considerably higher than those of joints containing hanging-downs of weld metal. As the root gaps of joints become wide, hangingdowns of weld metal become remarkable and fatigue strengths decrease.

(2) Fatigue crack originates at the one corner of root gap in the concave portion of hanging-downs, and propagates rapidly along the surface of weld metal at the root gap. Then, this crack grows to become penny-shaped crack.

(3) In the joints with hanging-downs of weld metal, fatigue cracks initiate and start to propagate at the early stage of life.

(4) In the joints with hanging-downs of weld metal, a large number of partially propagating fatigue cracks are observed at the concave portion of hanging-downs.

(5) Fatigue life of this joint can be predicted by using the fracture mechanics concepts. For this purpose, intial defect is regarded as a pennyshaped crack having a diameter equal to the width of root gap. Predicted stress rangefatigue life curves are close to the experimental results.

\section{ACKNOWLEDGEMENT}

The authors express their gratitude to Dr. Atsushi Okukawa of Honshu-Shikoku Bridge Authority for his valuable suggestion and to Mr. Takao Narumiya of Miyaji Iron Works for the fabrication of specimens.

\section{REFERENCES}

1) Nishimura, T., J. Tajima, A. Okukawa and C. Miki: Fatigue Strength of Longitudinal SingleBevel-Groove Welded Members, Proceedings of JSCE, No. 291, pp. $27 \sim 40$, Oct. 1979.

2) Miki, C., F. Nishino, Y. Hirabayashi and $H$. Ohga: Fatigue Strength of Longitudinal Welded Joints Containing Blowholes, Proceedings of JSCE, No. 325, pp. 155 166, Sept. 1982.

3) Miki, C., J. Tajima, K. Asahi and H. Takenouchi: Fatigue of Large-Size Partial Penetrated Longitudinal Butt Welds, Proceedings of JSCE, No. 322, pp. 143 156. June 1982.

4) Technical Committee for the Construction of Honshu-Shikoku Bridges, Kaiyoh Kakyo Chohsakai: Technical Report for the Construction of Stiffened Truss of Ohnaruto Bridge, 1982.

5) Matsuzaki, Y., H. Shimokawa and K. Murakami: Fatigue Design of the Honshu-Shikoku Bridges in Japan, IABSE Colloquium Lausanne 1982, pp. $497 \sim 502,1982$.

6) Miki, C., F. Nihsino and Y. Hirabayashi: Fatigue Crack Growth in the Corner Weld of BoxSection Bridge Truss Chord, IABSE Colloquium Lausanne 1982, pp. 345 352, 1982.

(Received January 25, 1983) 